\title{
Agglomeration economies, congestion diseconomies, and fertility dynamics in a two-region economy
}

\author{
Madoka Muroishi ${ }^{1} \cdot$ Akira Yakita $^{2}$ D
}

Received: 19 May 2020 / Accepted: 4 December 2020 / Published online: 3 January 2021

(C) The Author(s) 2021

\begin{abstract}
Using a small, open, two-region economy model populated by two-period-lived overlapping generations, we analyze long-term agglomeration economy and congestion diseconomy effects of young worker concentration on migration and the overall fertility rate. When the migration-stability condition is satisfied, the distribution of young workers between regions is obtainable in each period for a predetermined population size. Results show that migration stability does not guarantee dynamic stability of the economy. The stationary population size stability depends on the model parameters and the initial population size. On a stable trajectory converging to the stationary equilibrium, the overall fertility rate might change non-monotonically with the population size of the economy because of interregional migration. In each period, interregional migration mitigates regional population changes caused by fertility differences on the stable path. Results show that the inter-regional migration-stability condition does not guarantee stability of the population dynamics of the economy.
\end{abstract}

Keywords Agglomeration economies · Congestion diseconomies · Dynamic stability $\cdot$ Fertility $\cdot$ Migration $\cdot$ Stationary population

JEL Classification J13 · J61 $\cdot$ R11 $\cdot$ R23

\section{Introduction}

A negative relation between regional total fertility rates and population concentration in developed economies has been demonstrated empirically. This relation has been explained either as a consequence of urbanization processes (e.g., Sato and

Akira Yakita

yakita@nanzan-u.ac.jp

1 Graduate School of Economics, Nanzan University, Nagoya 466-8673, Japan

2 Faculty of Economics, Nanzan University, 18 Yamasato-cho, Showa-ku, Nagoya 466-8673, Japan 
Yamamoto 2005) or as a reflection of cross-sectional regional variation in fertility (e.g., Sato 2007). Whichever explanation is considered, concentration of population plays an important role in shaping the relation. In fact, population concentration engenders both agglomeration economies and congestion diseconomies. The prevailing negative relation between fertility and the population concentration implies that migration flows of young workers occur from regions of high fertility and low population concentration to regions of low fertility and high population concentration. This paper specifically examines cross-sectional regional variations in fertility and interregional migration. The main target of elucidation is their effects on the prevailing overall fertility rate of the economy over the long term.

Numerous reports of the literature have described interregional migration since publication of seminal papers by Todaro (1969) and Harris and Todaro (1970). Nevertheless, only recently have fertility decisions of individuals been incorporated into theoretical models. Zhang (2002) and Sato and Yamamoto (2005) present an analysis of how urbanization and demographic transition affect the average wage rate and the total fertility rate in economic growth settings. By contrast, Sato (2007) analyzes cross-regional variations in fertility by confining his analytical emphasis on the steady state. However, interregional migration might generally affect the overall fertility dynamics of the economy.

As described herein, we present an analysis of the long-term fertility rate of the economy by extending the theoretical analysis of Sato (2007) in two directions. First, we analyze fertility dynamics without restriction to a steady-state population size. Second, congestion diseconomies affect daily life. They derive from the concentration of young workers in the region, e.g., commuting time costs to the center of business. Fujita and Thisse (2013) describe that the urban cost function is convex in the number of urban workers. For these analyses, the costs of living are assumed to be nonlinearly increasing with the number of young workers in the region. ${ }^{1}$

Figure 1 portrays the relation between the municipal total fertility rate for 2008-2012 and the municipal population density in 2010 for 1739 Japanese municipalities. The population density is represented by the municipal population aged 15-64 per square kilometer of inhabitable land. A negative relation exists between them, but with some irregular extremes: the total fertility rate becomes lower as the population density becomes higher. ${ }^{2}$ The Family Income and Expenditure Survey (2017) also shows that workers younger than 40 spend a greater share of their income on housing than elderly people aged 60 and older in Japan. Moreover, it shows that commuting costs constitute a greater share of income for young workers aged 40-60 than for elderly people of 60 and older. These two facts imply that peer (external) effects of young workers raise

\footnotetext{
${ }^{1}$ This definition of congestion costs differs from that presented by Sato (2007), who regards congestion costs as those in the workplaces, as reflected in the decreasing marginal productivity of labor.

2 The correlation coefficient between these two variables in logarithms was -0.259 . The coefficient was -0.254 when the entire population is considered instead of those aged 15-64. De la Croix and Gobbi (2017) conclude from a study of world data collected over a long period that the population density negatively affects the fertility rate.
} 


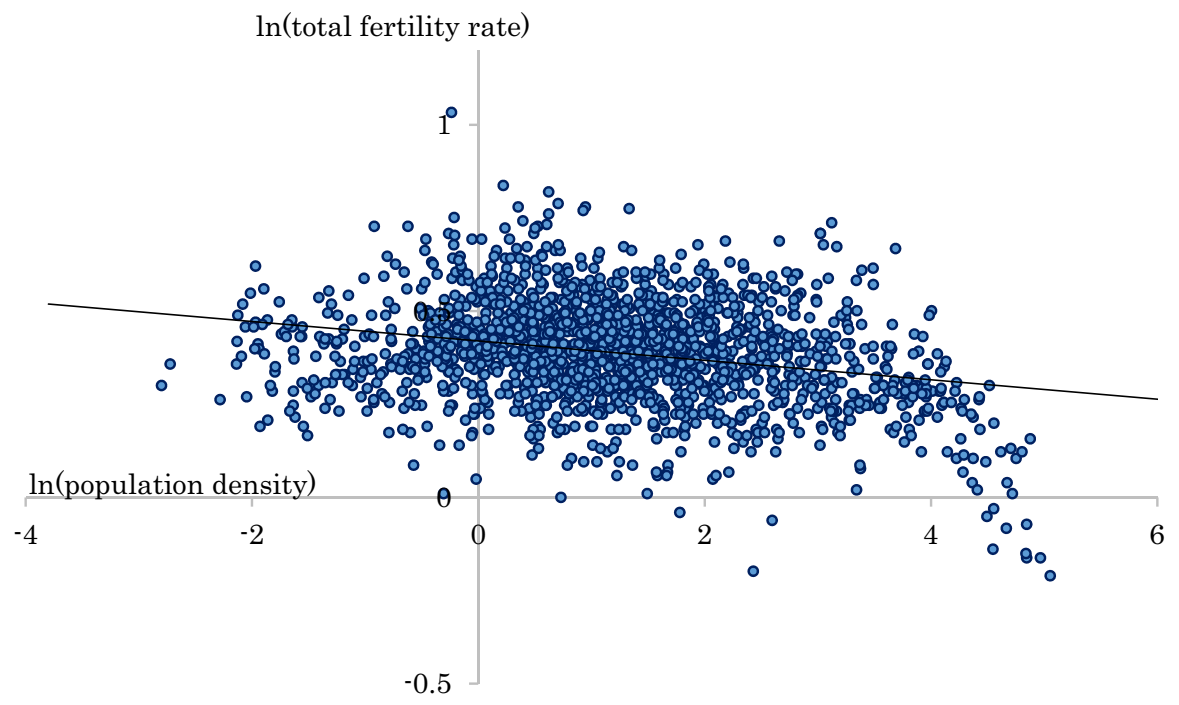

Fig. 1 Regional population density and regional total fertility rate in municipalities of Japan. The municipal population density is the population aged 15-64 per square kilometer of inheritable land in 2010: The total fertility rate is for the period of 2008-2012. Source: Population and areas of inhabitable land are calculated based on the System of Social and Demographic Statistics of Japan (Statistics Bureau, Ministry of Internal Affairs and Communications), and the municipal total fertility rates from Vital Statistics (Ministry of Health, Labour and Welfare)

productivity. They also imply that the concentration raises congestion costs in regions with high population density of young workers.

In a two-period overlapping generations model, individuals actively determine various economic problems such as where to reside, where to work, and how many children to have during the working period before retirement. Although Henderson (1974) describes that the average distance to the central business district increases commuting costs, Gaigné and Thisse (2009) assume that goods are sold at the same price irrespective of the customer location. Therefore, for the analyses presented in this paper, the concentration of young workers might be crucially important for individuals' determination of lifetime problems during the young period.

The main results are explained hereinafter. First, the interregional migration results analyzed by Sato (2007) also hold true in each period on a trajectory converging to a constant population steady state. Second, the migration-stability condition is necessary but insufficient for dynamic stability of the economy. Stability of the stationary equilibrium depends on model parameters and the initial population size. The scale of migration changes in the opposite direction to changes in the size of the entire population on a stable trajectory. ${ }^{3}$

\footnotetext{
3 After finishing these analyses, we find Goto and Minamimura (2019), who present analyses of demographic dynamics. Different from ours, their model is based on the new economic geography, emphasizing free trade and interregional migration without externalities.
} 
The next section introduces the model and characterizes the migration equilibrium prevailing in the respective period. Analyses of long-term paths of population and fertility are presented in Sect. 3. The dynamic stability condition and its relevance to the migration stability are discussed theoretically. Then, a numerical example illustrates some observations about the stable trajectory of fertility and population. Section 4 concludes the paper.

\section{Model}

We assume a small, open, two-region economy populated by two-period-lived overlapping generations. Individuals are identical in terms of preference, working and rearing children during the young period and being retired during the old period. Given a condition of free international capital mobility, the interest rate is given as the world interest rate, which is assumed to be constant over time. Land is owned by absentee landowners. Presuming that the areas of the two regions are identical and that each is normalized to one, the number of workers represents the density of the young generation. Each region has one central business district (CBD). All workers must commute to the CBD. Each worker consumes one unit of land in each region, receiving the same wage rate. When the sum of commuting costs to the $\mathrm{CBD}$ and land rent is common for all workers in a region, they have no incentive to move to another location within the region, i.e., intra-region spatial (or residential) equilibrium. $^{4}$

However, young workers are perfectly mobile between regions at the beginning of the young period. ${ }^{5}$ Regions differ in terms of their agglomeration economy intensity. If a young worker obtains higher expected utility by residing in the other region, then the worker moves to that region. The concentration of workers affects both the agglomeration benefits and the congestion costs within the region through externalities, i.e., a move of a young worker from one region to another affects the utility levels in both regions in opposite directions. Therefore, the arbitrage behaviors of young workers equalize the levels of their lifetime utility between the two regions, retaining spatial equilibrium in each region.

\subsection{Individuals}

We assume that the lifetime utility of an individual working in region $i$ in period $t$ is represented as a Cobb-Douglas type function as

\footnotetext{
${ }^{4}$ We assume that each region has sufficiently units of land.

5 The distribution of old retirees is already determined at the beginning of a period when young workers choose a region in which to live. We assume here that retirees cannot move between regions because of the prohibitively high cost.
} 


$$
u_{i}=c_{i t+1}^{\alpha} n_{i t}^{\beta}(0<\alpha, \beta<1 ; \alpha+\beta=1)
$$

where $c_{i t+1}$ stands for retirement consumption in period $t+1$ and where $n_{i t}$ is the number of children the individual has. For expositional simplicity, we omit consumption during the working period and assume that the entire earned wage income during the young period, less the congestion costs, is saved for retirement. ${ }^{6}$ Assuming the child-rearing time per child as constant at $b>0$, then the budget constraint during the young period is given as

$$
\left(1-b n_{i t}-g N_{i t}^{\delta}\right) w_{i t}=s_{i t}
$$

where $w_{i t}$ denotes the wage rate in region $i$ in period $t$. The time endowment of each worker during the working period is assumed to be one. Furthermore, $s_{i t}$ denotes savings for retirement consumption. Term $g N_{i t}^{\delta}>0$ stands for congestion diseconomy (time) costs, where $N_{i t}$ stands for the number of workers in region $i, \delta$ is a parameter reflecting the intensity of the congestion diseconomies $(0<\delta)$, and $g$ is a scale parameter of the diseconomies $(g>0){ }^{7}$ The congestion diseconomies are external effects to each worker in the region: no worker can control the effects. The congestion effects are attributable to the worker concentration. ${ }^{8}$ The budget constraint during retirement is

$$
R s_{i t}=c_{i t+1}
$$

where $R$ stands for the (gross) world interest rate.

From utility maximization behavior, we obtain the optimal consumption and number of children as ${ }^{9}$

$$
\begin{gathered}
c_{i t+1}=\alpha R w_{i t}\left(1-g N_{i t}^{\delta}\right) \\
n_{i t}=\frac{\beta}{b}\left(1-g N_{i t}^{\delta}\right)
\end{gathered}
$$

The number of children depends solely on congestion costs. The worker concentration depresses the fertility rate.

Inserting (4) and (5) into utility function (1), we obtain the indirect utility function of the individual as

$$
V_{i t}=\alpha^{\alpha} R^{\alpha} \beta^{\beta} b^{-\beta} w_{i t}^{1-\beta}\left(1-g N_{i t}^{\delta}\right)
$$

\footnotetext{
${ }^{6}$ Such a type of utility engenders no fundamentally important difference, even if considering consumption when young.

${ }^{7}$ This assumption is consistent with that proposed by Fujita and Thisse (2013), who describe that the urban cost function is convex in the number of urban workers.

${ }^{8}$ In contrast, Brinkman (2016), among others, describes that wage income in the budget constraint is the wage the person earns minus commuting costs.

${ }^{9}$ These optimal plans provide an upper limit of the number of workers in the region, i.e., $N_{i t} \leq g^{-1 / \delta}$.
} 


\subsection{Production}

The production technology of consumption goods in region $i$ is assumed to be represented by a Cobb-Douglas function as

$$
y_{i t}=A N_{i t}^{\varepsilon_{i}} L_{i t}^{\mu} K_{i t}^{1-\mu}(0<\mu<1 ; A>0)
$$

In that equation, $L_{i t}$ and $K_{i t}$ respectively denote the labor employed and capital stock in region $i$ in period $t$. Agglomeration economy effects are assumed to be represented as $\tilde{A} N_{i t}^{\varepsilon_{i}}$, where $\varepsilon_{i}$ denotes the intensity of agglomeration economies $\left(0<\varepsilon_{i}\right.$; $i, j=1,2)$ and where $\tilde{A}$ denotes a scale parameter of the agglomeration effect $(0<\tilde{A}<\infty)$. The agglomeration economies are external effects accruing to each producer in the region. The effects are generated by the concentration of young workers in the region. ${ }^{10}$ Scale parameter $A$ in the production function includes $\tilde{A}$. Labor is equal to the working time per worker times the number of workers as $L_{i t}=\left(1-b n_{i t}-g N_{i t}^{\delta}\right) N_{i t}$.

The profit maximization problem in region $i$ is to maximize.

$$
\pi_{i t}=A N_{i t}^{\varepsilon_{i}} L_{i t}^{\mu} K_{i t}^{1-\mu}-w_{i t} L_{i t}-R K_{i t}
$$

where $\pi_{i t}$ stands for the profit of producers in region $i$. The first-order conditions for profit maximization are

$$
\begin{gathered}
\mu A N_{i t}^{\varepsilon_{i}} L_{i t}^{\mu-1} K_{i t}^{1-\mu}-w_{i t}=0 \\
(1-\mu) A N_{i t}^{\varepsilon_{i}} L_{i t}^{\mu} K_{i t}^{-\mu}-R=0
\end{gathered}
$$

From these conditions, we obtain the wage rate in region $i$ in period $t$ as

$$
w_{i t}=\mu\left(\frac{1-\mu}{R}\right)^{(1-\mu) / \mu} A^{1 / \mu} N_{i t}^{\varepsilon_{i} / \mu} \equiv H N_{i t}^{\varepsilon_{i} / \mu}
$$

where $H \equiv \mu\left(\frac{1-\mu}{R}\right)^{(1-\mu) / \mu} A^{1 / \mu}$.

\subsection{Region choice of young workers between regions}

Young workers move between regions to obtain higher lifetime utility. Therefore, their arbitraging behaviors engender an equilibrium in migration such as $V_{1 t}=V_{2 t}$. Consequently, the distribution of young workers is found. From (6) and (10), we have

\footnotetext{
${ }^{10}$ We assume that the agglomeration intensity depends on $N_{i t}$, following Sato (2007). Fujita and Thisse (2013) describe that the spread of information among close-knit workers engenders an external effect. The number of workers apparently matters more than the working periods there.
} 


$$
V_{i t}=B w_{i t}^{1-\beta}\left(1-g N_{i t}^{\delta}\right)=B H^{1-\beta} N_{i t}^{(1-\beta) \varepsilon_{i} / \mu}\left(1-g N_{i t}^{\delta}\right) \equiv V_{i t}\left(N_{i t}\right)
$$

where $B \equiv \alpha^{\alpha} R^{\alpha} \beta^{\beta} b^{-\beta}$. Therefore, we obtain the arbitrage condition as

$$
V_{1 t}\left(N_{1 t}\right)=V_{2 t}\left(N_{2 t}\right), \text { where } N_{1 t}+N_{2 t}=N_{t}
$$

In that equation, $N_{t}$ denotes the total number of workers in the economy, which is determined already at the beginning of period $t$. From these two Eqs. (12), we obtain the equilibrium regional numbers of young workers in the two regions $\left(N_{1 t}, N_{2 t}\right)$ as functions of $N_{t}$. As usual in the literature of regional economics, the stability condition of migration can be given by the following lemma.

Lemma 1 (migration-stability condition) For the equalized utility $V_{1 t}=V_{2 t}$ to be stable at $0<N_{i t}<N_{t}$ for all $t$, it must hold that $d V_{1 t} / d N_{1 t}+d V_{2 t} / d N_{2 t}<0$, where

$$
\frac{d V_{i t}}{d N_{i t}}=B H^{1-\beta}\left(\frac{(1-\beta) \varepsilon_{i}}{\mu}-g\left[\delta+\frac{(1-\beta) \varepsilon_{i}}{\mu}\right] N_{i t}^{\delta}\right) N_{i t}^{(1-\beta) \varepsilon_{i} / \mu-1}
$$

It is noteworthy that $d V_{i t} / d N_{i t}$ can be positive for one region under the stability condition. For a sufficiently small number of workers, the term is positive. ${ }^{11}$ For migration stability, a young worker is worse off after moving from a region to another. Given a worker distribution of $\left(N_{1 t}, N_{2 t}\right)$, a worker in region 1 loses lifetime utility $d V_{1 t} / d N_{1 t}$ and gains $d V_{2 t} / d N_{1 t}$ by moving to region 2 . If the net gain is negative, i.e., $d V_{1 t} / d N_{1 t}+d V_{2 t} / d N_{2 t}<0$, where $d N_{1 t}+d N_{2 t}=0$, then this worker does not move. It is noteworthy that each region is in intra-region spatial equilibrium in the inter-region migration equilibrium.

This result differs from the result described by Sato (2007), who defines the effects exerted through parameters $\varepsilon_{i}$ and $\mu$ on the production side, respectively, as agglomeration economies and congestion diseconomies. By contrast, we assume nonlinear time costs of a congestion diseconomy. If the congestion exerts a great diseconomy effect, then the migration stability tends to hold true, ceteris paribus. ${ }^{12}$

Under the migration-stability condition, the following results are obtained with respect to the worker distribution in each period.

Lemma 2 If the (gross) agglomeration economy effect in region 1 is greater than that in region 2 , i.e., if $\varepsilon_{1}>\varepsilon_{2}$, then

(i) region 1 has a greater number of young workers, i.e., $N_{1 t}>N_{2 t}$;

(ii) the wage rate in region 1 is higher than in region 2, i.e., $w_{1 t}>w_{2 t}$; and

(iii) the regional fertility rate in region 1 is lower than in region 2, i.e., $n_{1 t}<n_{2 t}$.

$\overline{11} d V_{i t} / d N_{i t} \stackrel{>}{=} 0$ as $\left\{g\left[1+\delta \mu /(1-\beta) \varepsilon_{i}\right]\right\}^{-1 / \delta} \stackrel{>}{=} N_{i t}$.

${ }^{12}$ We assume away all mobility costs between regions. Zhang (2002) emphasizes the importance of moving costs. 
Proof See Appendix for (i). Results (ii) and (iii) are obtained respectively from Eqs. (10) and (5).

These results for interregional fertility and worker population distribution in a period are similar to those for the steady state described by Sato (2007). However, the logic underpinning our study differs from his: we assume nonlinear congestion time costs. The fertility rate in a region depends solely on the intensity of congestion diseconomy effects $(\delta)$. If daily life congestion becomes heavy, then the residences in the region decrease the number of children (Eq. 5). By contrast, agglomeration economies do not affect the regional fertility rate. The regional wage rate depends on agglomeration effects. A region with stronger agglomeration economy effects attracts more young workers from the other region through interregional migration, ceteris paribus. A greater degree of congestion diseconomy is likely to mitigate the worker concentration in a region with a high intensity of agglomeration economies; it is also likely to stabilize migration between regions (Eq. 13). Such effects of congestion diseconomies are not considered by Sato (2007). These results described in Lemma 2 are apparently consistent with the fact presented in Fig. 1.

From (8) and (9), we have $[(1-\mu) / \mu R] w_{i t}=K_{i t} / L_{i t}$, where $w_{1 t}>w_{2 t}$ when $\varepsilon_{1}>\varepsilon_{2}$ from Lemma 2. Therefore, it follows that $K_{1 t} / L_{1 t}>K_{2 t} / L_{2 t}$. The physical capital labor ratio in region 1 is greater than that in region 2 when agglomeration economies in region 1 are stronger. Each unit of working time in region 1 attracts more capital for goods production, although congestion reduces the working time per worker in region 1 more than it does in region 2.

\section{Long-term fertility rate of the economy}

This section presents consideration of the fertility dynamics of the economy. The overall fertility rate of the economy is given by the average of the two regional fertility rates weighted by the proportion of young workers as

$$
n_{t}=n_{1 t}\left(N_{1 t} / N_{t}\right)+n_{2 t}\left(N_{2 t} / N_{t}\right)
$$

The number of children a young worker has in each region depends on the model parameters. If the per-child rearing time is sufficiently small relative to the degree of preference for having children, i.e., if $\beta / b$ is sufficiently greater than one, then we have $n_{i t} \geq 1$. However, the fertility rate of the economy $n_{t} \equiv N_{t+1} / N_{t}$ might be greater than, equal to, or less than one, depending on the parameters. We cannot rule out any of these three possibilities a priori.

The law of movement of the population size is given for initial value $N_{0}$ by (14) as

$$
N_{t+1}=n_{1 t} N_{1 t}+n_{2 t} N_{2 t}
$$

where $N_{2 t}=N_{t}-N_{1 t}$. 
We first consider the local stability condition of the stationary population size, which is given as

$$
-1<\frac{d N_{t+1}}{d N_{t}}<1
$$

where the derivatives are evaluated at the stationary value. From (5) and (15), we obtain

$$
\frac{d N_{t+1}}{d N_{t}}=\frac{\beta}{b}\left[1-(1+\delta) g N_{1 t}^{\delta}\right] \frac{d N_{1 t}}{d N_{t}}+\frac{\beta}{b}\left[1-(1+\delta) g N_{2 t}^{\delta}\right] \frac{d N_{2 t}}{d N_{t}}
$$

Differentiating the migration equilibrium condition (12), we obtain changes in the regional population of workers when the total population size changes. The regional number of workers is given as determined after interregional migration is stabilized. We quantify the effects of the entire worker population change on the regional number of workers from (12) as

$$
\frac{d N_{i t}}{d N_{t}}=\frac{d V_{j t} / d N_{j t}}{d V_{1 t} / d N_{1 t}+d V_{2 t} / d N_{2 t}} \quad(i, j=1,2 ; i \neq j)
$$

The denominator of the right-hand side of (18) is negative from the migrationstability condition (Lemma 1). The sign of the numerator on the right-hand side is ambiguous, as might be apparent from (13) and footnote 9. Using (17) and (18), the stability condition (16) can be written as

$$
-1<\frac{\beta}{b} \frac{\left[1-(1+\delta) g N_{1}^{\delta}\right]\left(d V_{2 t} / d N_{2 t}\right)}{d V_{1 t} / d N_{1 t}+d V_{2 t} / d N_{2 t}}+\frac{\beta}{b} \frac{\left[1-(1+\delta) g N_{2}^{\delta}\right]\left(d V_{1 t} / d N_{1 t}\right)}{d V_{1 t} / d N_{1 t}+d V_{2 t} / d N_{2 t}}<1
$$

where the functions are evaluated in the stationary equilibrium. The migrationstability condition of $d V_{1 t} / d N_{1 t}+d V_{2 t} / d N_{2 t}<0$, does not guarantee the dynamic (local) stability of the population size. Therefore, the dynamic stability condition of the system (19) must be distinguished from the static migration-stability condition. With respect to the local stability of the dynamic system, we have the following proposition. ${ }^{13}$

Proposition 1 The condition for migration stability does not guarantee the dynamic stability of the fertility dynamics, although migration stability is necessary for dynamic system stability.

The stability of population dynamics depends on the model parameters, as might be apparent from (13) and (19). Condition (19) is nonlinear in model parameters. Therefore, it is difficult to derive the dynamic stability condition in a general form

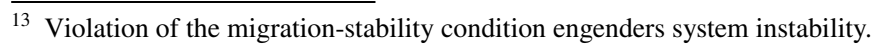


using those parameters. If condition (19) is not satisfied, then the population dynamics becomes unstable. The population size expands or shrinks as time passes.

In addition, if the initial population size is too great, then the fertility rate chosen by workers in a region might become negative (Eq. 5). Congestion diseconomies depress worker's time and income for rearing children with given parameters, as described in (2). The fertility rate must be non-negative. Therefore, the stability condition also depends on the population size at the time of fertility decisions, in addition to the model parameters. It is also noteworthy that, on the trajectory to the stationary equilibrium, young workers move between regions to equate their utility levels. The number of workers in a region is not equal to the number of children born in that region. It is the sum of native children and migrants, although the latter might be negative. Therefore, the worker population size, on which the fertility decision at the beginning of each period is based, depends on the scale of migration. In each period, the migration-stability condition must be satisfied. Therefore, regional fertility rates and interregional migration directly influence the motion of the entire population. In a stationary equilibrium, regional fertility rates also remain constant. Therefore, migration between regions becomes constant. These arguments are related directly to the global stability of the population dynamics. To sum up the arguments presented above, we have the following proposition related to global stability.

Proposition 2 Presuming the existence of a stationary trajectory converging to an equilibrium, we obtain the following points.

(i) The stability of fertility dynamics depends on the intensities of agglomeration economies and congestion diseconomies, and on the initial population size.

(ii) On a stable trajectory converging to stationary equilibrium, the relation between the population size and the fertility rate is not necessarily monotonical.

(iii) On a stable trajectory, the scale of migration from region 2 to region 1 decreases (increases) as the population size of the economy increases (decreases) toward a stationary equilibrium.

The next section presents a numerical example of a stable population dynamic path.

\subsection{Numerical example}

The following parameters are assumed: child-rearing time $b$ of 0.075 , as presented by de la Croix and Doepke (2003); labor elasticity in goods production $\mu$ of 0.6 , as reported in the literature; and gross interest rate $R$ for one period (i.e., for about 25-30 years) of 2.94. For convenience of exposition, we set other parameters as $\left(\beta, g, \varepsilon_{1}, \varepsilon_{2}, \delta\right)=(0.235,0.004,1.2,1.1,1.3)$. The initial population size of the 


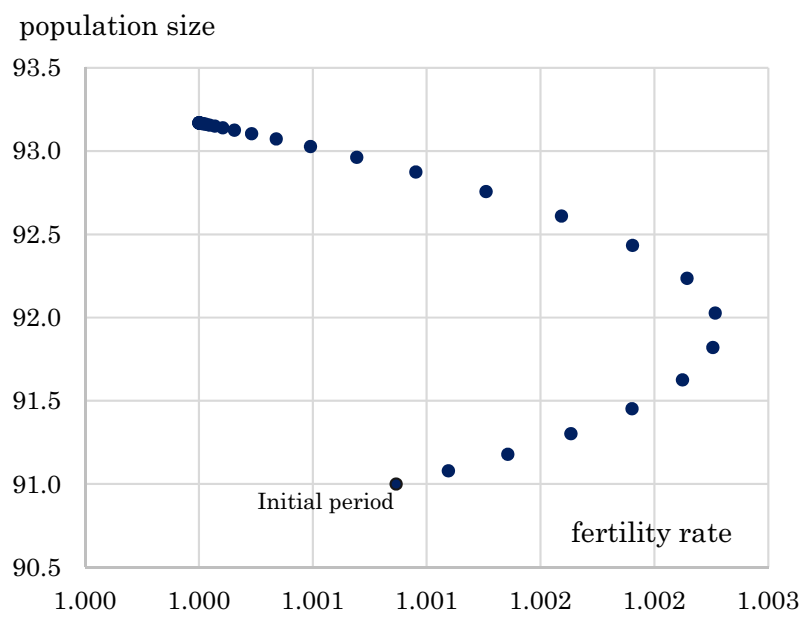

Fig. 2 Time paths of the population size and fertility rate of the economy

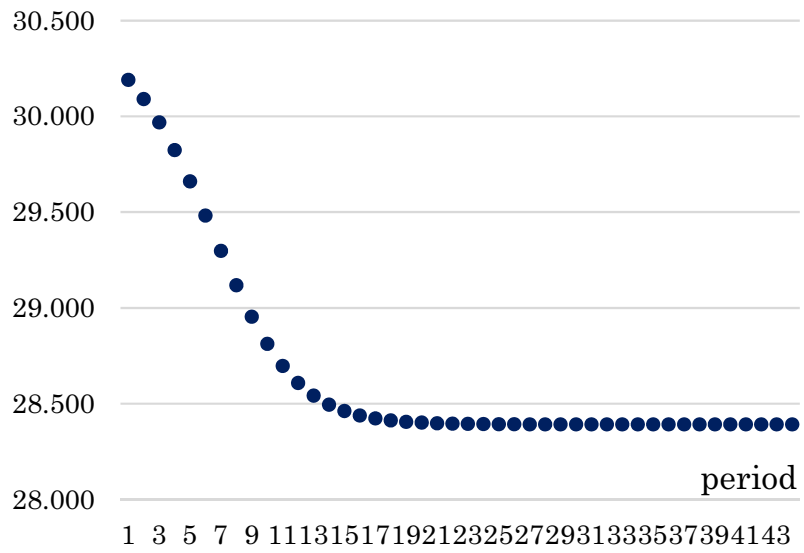

Fig. 3 Time path of migration

economy $\left(N_{0}\right)$ is assumed to be 91 to obtain a stable fertility path. Stable paths of fertility and the population size are presented in Fig. 2 for the entire economy.

These movements can be interpreted as follows: In every period, workers move between regions. In the initial period, because of agglomeration economies, region 1 attracts more workers than region 2. Congestion diseconomies lower the fertility rate in region 1 through the income effect. Although the fertility rate is lower in region 1 , workers inflow from region 2 to the degree that the agglomeration effects are dominant. The decrease in population caused by low fertility is partly mitigated by worker inflows. However, the migrant inflow exacerbates congestion diseconomies, thereby decreasing the attractiveness of agglomeration economies. Figure 3 presents 
the time path of migration from region 2 to region 1 . The movement decreases as the economy approaches a stationary equilibrium.

It is noteworthy that changes in parameters and the initial population size might lead to instability of the population dynamics as discussed in Proposition 2.

\section{Concluding remarks}

High intensity of agglomeration economy attracts young workers, lowering the regional fertility rate because of congestion diseconomy. Differences in agglomeration intensity engender migration between regions. The overall fertility rate of the economy is characterized as the average of regional fertility rates weighted by the respective regional shares of young workers.

The migration-stability condition does not guarantee dynamic stability of the economic system. Interregional movements of workers mitigate population changes caused by fertility differences in the respective regions. Therefore, the severest policy issue of fertility changes might be (global) instability of the dynamic populationsize path with interregional migration.

One limitation of the model presented herein is the assumption of a small open economy. The interest rate is fixed at the world level. Capital moves internationally and freely. Therefore, the link between domestic savings and domestic capital formation is absent. Differences in the strength of agglomeration economies affect the regional allocation of capital, which in turn influences the regional distribution of workers. Analyzing these interactions between regional migration and capital accumulation necessitates the retention of links between savings and capital formation. ${ }^{14}$ Such an analysis remains as a subject to be addressed in future research efforts.

Acknowledgements The authors thank anonymous referees for their insightful comments and suggestions. An earlier version of this paper was presented at the 2019 Autumn Meeting of the Japan Association for Applied Economics, the 2019 Taiwan Economic Association Annual Conference, and the Nagoya Macroeconomics Workshop. The authors thank Yasuhiro Sato and Shin-Kun Peng for their insightful comments and discussions. They are also indebted to session participants for helpful comments they offered. The second author acknowledges financial support from the Japan Society for the Promotion of Science KAKENHI [Grant No. 19H01503].

Data availability Data sharing is not applicable to the study described in this paper: no new data were analyzed.

\section{Compliance with ethical standards}

Conflict of interest The authors have no conflict of interest, financial or otherwise, related to this study.

Open Access This article is licensed under a Creative Commons Attribution 4.0 International License, which permits use, sharing, adaptation, distribution and reproduction in any medium or format, as long as you give appropriate credit to the original author(s) and the source, provide a link to the Creative Commons licence, and indicate if changes were made. The images or other third party material in this article

\footnotetext{
${ }^{14}$ Along these lines of study, Yakita (2011), among others, recently present long-term analyses of fertility dynamics and capital accumulation.
} 
are included in the article's Creative Commons licence, unless indicated otherwise in a credit line to the material. If material is not included in the article's Creative Commons licence and your intended use is not permitted by statutory regulation or exceeds the permitted use, you will need to obtain permission directly from the copyright holder. To view a copy of this licence, visit http://creativecommons.org/licen ses/by/4.0/.

\section{Appendix}

\section{Proof of Lemma 2 (1)}

Considering region choices of workers for a given population of young workers in a period, then for $\bar{N}=N_{1 t}=N_{2 t}$, we have $n_{1 t}=n_{2 t}$ from (5) and $w_{1 t}>w_{2 t}$ from (10). Therefore, because $V_{i t}=(b B / \beta) w_{i t}^{1-\beta} n_{i t}$, we have $V_{1 t}(\bar{N})>V_{2 t}(\bar{N})$ when $\varepsilon_{1}>\varepsilon_{2}$. Next, one can consider $N_{1 t}(v)$ and $N_{2 t}(v)$ such that $V_{1 t}\left(N_{1 t}(v)\right)=V_{2 t}\left(N_{2 t}(v)\right)=v$ for $\varepsilon_{1}>\varepsilon_{2}$. Assuming that $N_{1 t}(v) \leq \bar{N} \leq N_{2 t}(v)$, then increasing $N_{1 t}$ slightly from $N_{1 t}(v)$ gives $V_{1 t}\left(N_{1 t}\right)<v$ because $d V_{1 t} / d N_{1 t}<0$. Furthermore, decreasing $N_{2 t}$ slightly from $N_{2 t}(v)$ gives $V_{2 t}\left(N_{2 t}\right)>v$ because $d V_{2 t} / d N_{2 t}<0$. Therefore, we obtain $V_{1 t}\left(N_{1 t}\right) \leq v \leq V_{2 t}\left(N_{2 t}\right)$ for $N_{1 t}(v) \leq N_{1 t} \leq \bar{N} \leq N_{2 t} \leq N_{2 t}(v)$. These findings contradict the fact that $V_{1 t}(\bar{N})>V_{2 t}(\bar{N})$ for the same $\bar{N}$ when $\varepsilon_{1}>\varepsilon_{2}$. Therefore, we must have the result. Q.E.D.

\section{References}

The Ministry of Internal Affairs and Communications. The family income and expenditure survey 2017. Statistics Bureau of Japan, the Ministry of Internal Affairs and Communications in Japan. http:// www.stat.go.jp/english/data/kakei/index.html (2007). Accessed 10 April 2020

Brinkman, J.: Congestion, agglomeration, and the structure of cities. J. Urban. Econ. 94, 13-31 (2016)

De la Croix, D., Gobbi, P.E.: Population density, fertility, and demographic convergence in developing countries. J. Dev. Econ. 127, 13-24 (2017)

De la Croix, D., Doepke, M.: Inequality and growth: why differential fertility matters. Am. Econ. Rev. 93(4), 1091-1113 (2003)

Fujita, M., Thisse, J.-K.: Economics of agglomeration, 2nd edn. Cambridge University Press, New York (2013)

Gaigné, C., Thisse, J.-F.: Aging nations and the future of cities. J. Reg. Sci. 49(4), 663-688 (2009)

Goto, H., Minamimura, K.: Geography and demography: new economic geography with endogenous fertility. Jpn. Econ. Rev. 70(4), 537-568 (2019)

Harris, J.R., Todaro, M.P.: Migration, unemployment and development: a two-sector analysis. Am. Econ. Rev. 60(1), 126-142 (1970)

Henderson, J.V.: The sizes and types of cities. Am. Econ. Rev. 64(4), 640-656 (1974)

Sato, Y.: Economic geography, fertility and migration. J. Urban. Econ. 61(2), 372-387 (2007)

Sato, Y., Yamamoto, K.: Population concentration, urbanization, and demographic transition. J. Urban. Econ. 58(1), 45-61 (2005)

Todaro, M.P.: A model of labor migration and urban unemployment in less developed countries. Am. Econ. Rev. 59(1), 138-148 (1969)

Yakita, S.: Regional public goods, migration, and growth. Lett. Spat. Resour. Sci. 4(2), 129-138 (2011)

Yakita, A.: Effects of capital taxation on economies with different demographic changes: short term versus long term. J. Popul. Econ. 27(1), 257-243 (2014)

Zhang, J.: Urbanization, population transition, and growth. Oxford Econ. Pap. 54(1), 91-117 (2002) 